\title{
Informing a social practice theory framework with social- psychological factors for analyzing routinized energy consumption: A multivariate analysis of three practices
}

\author{
Ann-Kathrin Hess ${ }^{\mathrm{a}^{*}}$, Robin Samuel ${ }^{\mathrm{b}}$, Paul Burger ${ }^{\mathrm{a}}$ \\ a Sustainability Research Group, University of Basel \\ ${ }^{\mathrm{b}}$ Research Unit INSIDE, University of Luxembourg \\ ${ }^{*}$ Corresponding author at: Sustainability Research Group, University of Basel, \\ Switzerland \\ E-mail address: ann-kathrin.hess@unibas.ch
}

Energy Research \& Social Science, Volume 46, December 2018, Pages 183-193.

Published online July 31, 2018.

(C) 2018. This manuscript version is made available under the CC-BY-NC-ND 4.0 license http://creativecommons.org/licenses/by-nc-nd/4.0/

The final publication is available via doi:10.1016/j.erss.2018.06.012.

\begin{abstract}
A key factor contributing to the non-realization of energy efficiency potentials is the routinized way in which many energy consumption behaviors (ECBs) are performed. To analyze routinized ECBs, we draw on social practice theory and psychological concepts and suggest a framework that considers individual, social, and material factors. Based on our proposed framework and employing multivariate regression analysis, we gain new insights into associated factors of routinized ECBs-particularly for washing and drying clothes and showering. Analyzing data from a survey conducted among Swiss households in 2016 ( $n=5015)$, we find that individual values, practice-specific wants, and materials explain variations in routinized ECB performance. Furthermore, socio-demographic predictors shed light on cultural and status differences associated with routinized ECBs. This paper contributes to understanding associated factors of routinized ECBs by bridging practice theory and psychology-based factors.
\end{abstract}

Keywords:

Energy consumption

Routines

Social-psychological determinants

Social practice theory 


\section{Introduction}

Designing effective interventions to reduce household energy consumption requires an understanding of the explanatory factors of routinized energy consumption behaviors (ECBs). Gaining such insights is of paramount importance for at least three reasons. First, routinization might explain why energy consumption increases despite awareness and knowledge about how to save energy [1]. Second, a huge share of our behaviors are habitual. Wood et al. [2] found that $88 \%$ of hygiene and appearance behaviors are habits (i.e., performed frequently and in stable contexts). Third, a considerable carbon-saving potential is associated with habitual behavior changes. Dietz et al. [3] estimated an annual saving potential of 2.2 million metric tons of carbon after 10 years, if $35 \%$ of the U.S. population, that are not yet performing the behavior, were to line dry clothing.

Over the past few decades, our understanding of routinized ECBs has improved remarkably. Social practice theory (SPT) has informed many empirical studies on routinized behaviors, such as washing clothes [4,5], line drying [6], and showering [7]. A main finding was that routines evolve in an interplay of technology, social norms, and everyday life. These studies also considered historical narratives and technological developments [4], social relations [5], as well as individual circumstances [7] that play a role in the performance of practices.

In a parallel research strand, few studies rooted in environmental and social psychology analyzed routinized behaviors. However, several analyzed psychological and sociodemographic predictors of curtailment behavior, comprising daily life ECBs [8]. Psychological predictors include concerns about energy security, personal and social norms, and environmental and financial motivation [8]. Socio-demographic predictors include age, gender, education, and income [8].

Although SPT and psychology scholars share an interest in understanding "repetitive climate-relevant actions" [9], the two perspectives are often presented as contrapositions $[6,10]$. The epistemological differences between SPT and theories of behavior are rooted in conflicting conceptualizations of the basis of action; in theories of behavior, the basis of action is individual choice, whereas in theories of practice, it is socially shared conventions [11]. Nevertheless, Kurz et al. [9] elaborated on how these approaches can benefit from one another: "the traditionally more individualistic approaches of social psychology can benefit [from considering] the material, procedural, and social structures that constitute [practices]" ([9], p. 123). In turn, SPT may engage with ideas from social psychology, which might offer useful conceptions "for both the theorizing and changing of the social meanings of practices” ([9], p. 124). We build on the suggestion by Kurz et al. [9] to analyze individual and structural factors of routinized ECBs.

SPT forms a heterogenous "family of theories" ([12], p. 244). However, most SPT approaches use practices as their smallest unit of analysis [12]. Reckwitz [12] described a practice as

a routinized type of behavior which consists of several elements, interconnected to one other: forms of bodily activities, forms of mental activities, "things" and their use, a background knowledge in the form of understanding, know-how, states of emotion and motivational knowledge. A practice [e.g., a way of cooking] forms so to speak a "block" whose existence necessarily depends on the existence and specific interconnectedness of these elements, and which cannot be reduced to any of these single elements (p. 249-250). 
Shove et al. [11] subsumed these features of practice into three categories: materials (infrastructures, tools, hardware), meanings (mental activities, emotions, motivational knowledge), and competences (know-how, background knowledge, general understandings, specific skills). Routinization is then understood as "ongoing accomplishments in which similar elements are repeatedly linked together in similar ways" (p. 24).

Within the SPT framework, a debate on the role of individual factors can be observed. In some SPT versions, people are seen as carriers of practice [11,12]; consequently, the profile and evolution of any practice depends "on changing populations of more and less faithful carriers or practitioners” ([11], p. 63). This view has been criticized by Piscicelli et al. [13] who stated that such SPT versions tend to overlook the role of the individual and its ability to negotiate conceptions of normality. This debate connects to the discussion on how the relationship between individuals and structures should be conceptualized. To overcome the agency-structure divide, Piscicelli et al. [14] suggested an individual-practice framework which acknowledges "the existing interaction between the carrier [i.e., the individual] and a specific configuration of 'material', 'competence' and 'meaning' elements” (p. 39). Similar concerns can be raised regarding the conceptual differentiation between practicesas-entity and practices-as-performance when analyzing variations within collectively shared practices. Practices-as-entity encompass socially embedded underpinnings of behavior, and practices-as-performances are the observable expressions (i.e., behaviors) of these social phenomena [15]. However, it is unclear in what way interaction and renegotiation between individuals and structures are considered within practices-asperformances. On an empirical level, there is evidence for individual or sub-group variations in the performance of collectively shared practices [5,7]. Furthermore, these variations can be explained by differences in norms (cultural norms and norms learned in childhood, but also norms that have developed through conscious reasoning) [5] and individual values [13]. Also, social-psychological studies [16] have repeatedly demonstrated that "there is no simple singular "public"” (p. 73). Instead, attitudes and risk perceptions need to be considered in the context of historical developments and local contexts [16].

Contributing to the debate on the relationship between individual and structural factors in explaining routinized ECBs is important for at least three reasons. First, individual variations may be considered niches for changes in routines, and, on a larger scale, for social change [17]. Second, this debate is a substantial research gap. In at least some SPT versions [11,15], structural factors are considered the decisive behavioral components (cf. [18] for a more general approach to framing factors). Third, complementing Piscicelli et al. [13,19], there is an emerging strand of research demonstrating how conceptual and empirical work that draws on SPT may benefit from integrating elements of social-psychological theorization and vice versa [9]. This is in line with often-made claims that disciplinary boundaries should be transcended to make progress in understanding changes in household energy consumption [6]. Nash et al. [20] elaborated on integrating SPT and psychological approaches to analyze and promote positive behavioral spillovers. The authors suggested that changes across different practices may co-occur with changes in competences (e.g., self-efficacy and skills) and meanings (e.g., goals and values). Boldero and Binder [10] have worked on localizing norms in an SPT framework by relying not only on SPT insights but also social-psychological understandings of norms and their contribution to changing routines.

Against that backdrop, our overarching goal is to contribute to explaining individual variations in routines and add empirical evidence to the debate on individual versus structural factors. Our conceptual starting points are the elements of practices in Shove et al.'s widely established framework [11], which operationalizes structural elements. 
Moreover, to analyze individual variations in routines, the different features of the elements of practice need to be clearly defined and operationalized. Here, we propose to use socialpsychological constructs for theoretical and empirical reasons. First, there are reliable and widely tested scales and theoretical foundations for approaching individual variations in a survey. Second, studies along that line of reasoning, such as Piscicelli et al. [13], have suggested that social-psychological constructs explain differences in the performance of a practice. Materials, meanings, and competences build our overarching analytical categories. With our contribution, we hope to demonstrate the benefit of an integrative approach for empirical work on routinized energy consumption.

\section{Analytical framework and hypotheses}

Many constructs that we integrate from social psychology research into our framework have been widely studied. Therefore, we refrain from stating hypotheses related to wellestablished claims (e.g., on values) and focus on developing hypotheses that draw on the integration of practice-specific wants and materials in explaining individual variations in routinized ECBs. In developing a framework, we draw on Shove et al.'s [11] triad: the meaning, competence, and material elements of practice. We acknowledge that all constructs (e.g., "values” or "norms") used to operationalize the elements of practice are not genuine social-psychological constructs but likewise exist in sociological theorizing. However, the literature and the scales we use originate from psychological research.

\subsection{The meaning element of practice}

Shove et al. [11] used the term meaning "to represent the social and symbolic significance of participation at any one moment” (p. 23). Based on previous empirical and theoretical insights from SPT and social-psychological approaches, we suggest that norms and values may help to identify individual variations in performances of practices. Furthermore, we include practice-specific wants as a related SPT construct.

\subsubsection{Norms}

The concept of social norms is part of the theory of planned behavior (TPB) [21], a widely used social-psychological theory of behavior. Including social norms in models to explain individual action can be regarded as including structures residing outside the individual [22]. However, the individual is still emphasized because the focus is on a person's perception of what others expect from him or her [22]. Thus, social norms operate on the interrelation between the other and the self. Norm-confirming behavior is socially rewarded and, therefore, is an important aspect of the social significance of a practice. Also, empirical research based on SPT has emphasized the role of norms in influencing routines [5].

In most social-psychological literature, three forms of norms are distinguished: injunctive, descriptive, and personal. The first two relate to "the other" and the last to "the self" (for a distinction between the three, see Cialdini et al. [23]). In a meta-analysis, Bamberg and Möser [24] found a relatively strong correlation between social norms and proenvironmental behavior $(r=0.31)$, as well as personal norms and pro-environmental behavior $(r=0.39)$. However, evidence of the influence of norms on specific and routinized ECBs is lacking.

We operationalize norms as a construct related to the meaning element of practice. For example, variations in the performance of the practice of tumble drying clothes can be an expression of different conventions and expectations [5]. In line with research on general pro-environmental behavior, we examine whether prevalent energy-saving norms in an agent's social environment can explain individual variation in routinized ECB performance. 


\subsubsection{Values}

Steg et al. [25] stressed the role of values in motivating ECBs. Values are guiding principles in a person's life and influence a range of beliefs, attitudes, and actions [25]. In environmental psychology, four relevant types of values (altruistic, biospheric, egoistic, hedonic) belong to Schwartz's [26,27] self-transcendence versus self-enhancement value dimension. Empirical research has revealed a positive association between altruistic and biospheric values and pro-environmental behavior and a contrasting relationship for egoistic and hedonic values $[25,28]$. This correlation has also been found for specific routinized behaviors, such as showering time [28]. Empirical research based on SPT has revealed that differences in value orientation help explain participation in the practice of collaborative consumption [13,19].

Building on these findings, we operationalize values as a construct related to the meaning element of practice. In line with environmental- and social-psychological theorizing, we examine whether differences in value orientations explain differences in routinized ECBs.

\subsubsection{Wants}

Aspirations are part of the meaning element of practice ([11], p. 14); however, when it comes to conceptualizing individual variations in practices, Schatzki's notion of practical intelligibility should be considered [5]. According to Schatzki [29], "practical intelligibility is what makes sense to a person to do" (p. 74-75) and as such governs actions. Schatzki [29] stressed that "practical intelligibility is an individualist phenomenon" and that "the features of individuals that determine practical intelligibility are in fact mental conditions. The ends, projects, and tasks that a person pursues, for instance, are objects of her or his desires and intentions” (p. 75).

Hence, we understand practice-specific wants as the degree to which certain materials, outcomes, and processes are important to a person, and thus, can explain individual variations in the performance of practices. The following hypotheses are derived from that understanding:

H1a: Wanting to wear fresh clothes every day is positively associated with the number of wash cycles.

H1b: Wanting to wear fresh clothes every day is positively associated with the number of drying cycles.

H1c: Wanting to take long showers is positively associated with the number of showers.

H1a and H1b may seem trivial, but wants often do not translate directly into actions and behaviors. Thus, it is worth testing the nature and extent of the association with routinized ECBs. H1c is further motivated by Browne et al. [7], who found a positive relationship between showering frequency and length for their "attentive cleaners" cluster.

\subsection{The competence element of practice}

In SPT, knowledge encompasses an implicit worldview [12]. However, real-world examples also point to individual skills. Driving a car, for example, requires knowledge of how to drive and maintain a vehicle [11]. Moreover, car-driving or any other action also requires the general belief that one can perform this action. Hence, the competence element of a practice may relate to the social-psychological concepts of factual knowledge and perceived self-efficacy.

\subsubsection{Factual knowledge}


Social-psychological theory presents knowledge as a factor underlying ECBs [25]. Empirical research has shown that knowledge about energy and climate change issues and problem-solving strategies are prerequisites for reducing one's own energy consumption [25]. Tobler et al. [30] suggested that factual knowledge about climate change and its causes is positively associated with concern about climate change and is negatively associated with skepticism and feelings of powerlessness. However, it has been shown that people do not consider carbon dioxide $\left(\mathrm{CO}_{2}\right)$ emissions and climate change in their daily behavior, and that knowledge does not necessarily translate into action [31]. Steg et al. [25] summarized that action-related and effectiveness knowledge are related to actual behavior, whereas system knowledge is only indirectly related to behavior via these other types of knowledge.

"Carbon capability" is based on an SPT framework and explicitly considers wider sociotechnical aspects in knowledge [31]. The focus is on "situated knowledge," that is, the translation and application of knowledge about carbon into daily life [31].

Our analysis would have benefited from operationalizing practice-related knowledge as "carbon capability" or "action-related knowledge." However, the items in our large-scale interdisciplinary household survey mainly measured "energy/carbon literacy.” Thus, we build on the factual knowledge literature, including the degree to which people know about energy generation sources, main consumption areas, and externalities. We assume that factual knowledge represents an understanding of the broader socio-technical context in which the behavior is embedded. We examine whether differences in factual knowledge are associated with differences in routinized ECBs. In line with the literature, which has not found a direct relation between factual knowledge and daily life behaviors [25,31], we assume that differences in factual knowledge play a minor role in explaining variation in routinized ECB performance.

\subsubsection{Self-efficacy}

A link between knowledge and perceived self-efficacy was suggested by Tobler et al. [30], whereby people who know about climate change and its causes feel they might contribute to climate protection. Two dimensions constitute self-efficacy-outcome expectancy (i.e., the perception that one's own behavior has an impact) and efficacy expectation (i.e., the belief that one is able to realize a certain behavior) [32]. Self-efficacy is compatible with perceived behavioral control in the TPB [21]. An individual's perception of his or her ability to perform a behavior influences his or her actual conduct; when perceived control reflects actual control, then perceived control is considered a direct determinant of behavior $[21,32,33]$. Ajzen [21] shared an example of two persons who show the same intention to learn to ski; the person who is confident about his or her ability is more likely to succeed than the other person.

We focus on efficacy expectation and operationalize this construct in relation to the competence element of practice. In line with the TPB, we expect that efficacy expectation is negatively associated with the frequency with which the three routinized ECBs that we analyze are performed. For example, if a person believes he or she knows how to behave in an environmentally friendly way, then this belief should be associated with less tumble dryer usage. As research on the association between specific routinized behaviors and environmental self-efficacy is scarce, we explore this association but cannot derive and test formal hypotheses.

\subsection{The material element of practice}

Materials are objects, infrastructures, tools, hardware, and the body itself [11]. Changes in practices are related to technological development; for example, the emergence of the washing machine and tumble dryer influenced washing practices [4,5]. Materials can be 
viewed as spanning the social and individual opportunity space [18], as the availability of certain equipment might explain differences in ECBs.

In the present study, the washing machine and the tumble dryer are the relevant materials for the laundry practice. However, due to filtering in the survey, only a sub-sample of households that had a washing machine and a tumble dryer for private use was asked about the performance of washing and drying.

For showering, the number of bathrooms is the relevant material, and we tested the following hypothesis:

H2: The number of bathrooms is positively associated with the number of showers.

Fig. 1 provides an overview of the main elements of the analytical framework.

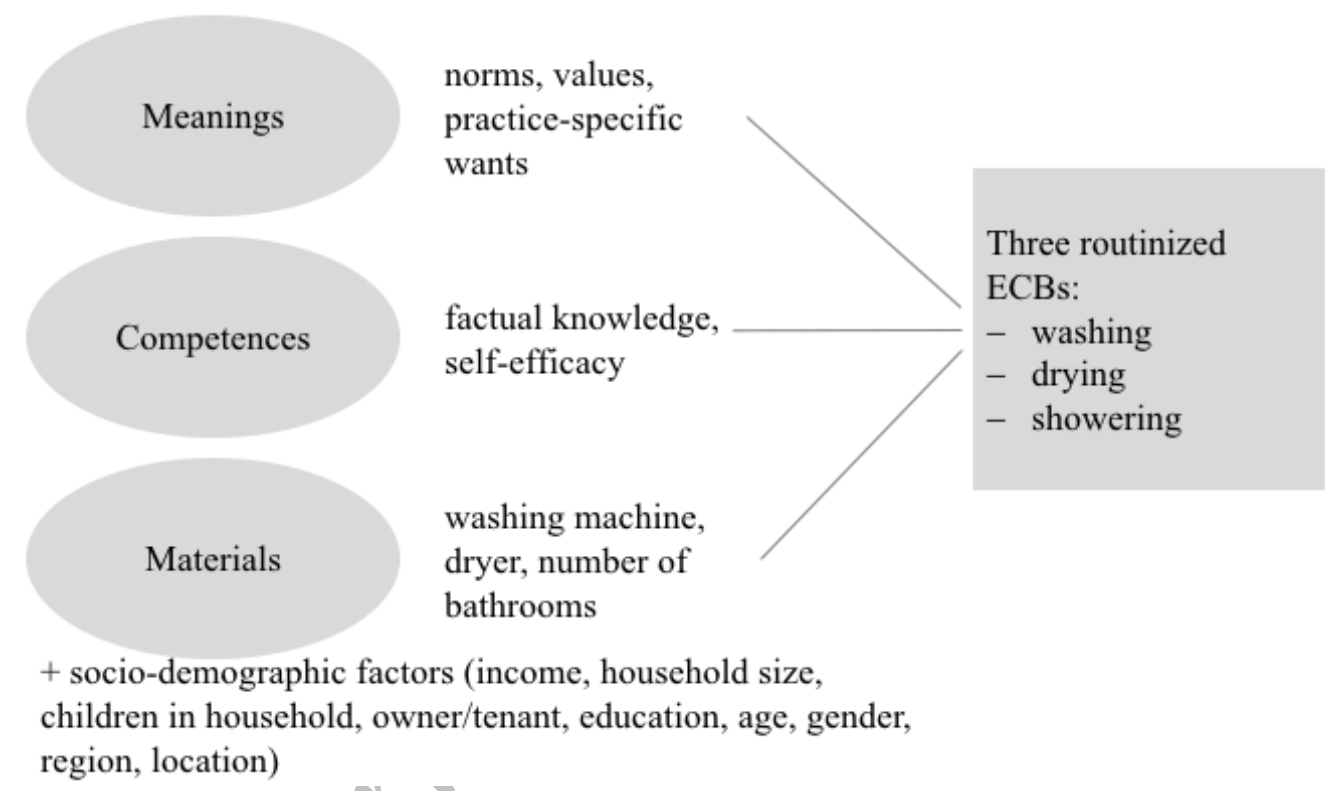

Fig. 1. Analytical framework.

\section{Material and methods}

\subsection{Sample}

The study draws on data from the first wave of the Swiss Household Energy Demand Survey (SHEDS). The survey was designed by researchers from the Swiss Competence Center for Research in Energy, Society and Transition (SCCER CREST) Working Package 2 [34] and administered in collaboration with intervista AG. Respondents were recruited from the intervista online access panel [35] and offered an incentive (bonus points) for answering the survey. Participants were invited to take the survey until a sample size of approximately 5,000 was reached. To get a sample that was representative of the population in Switzerland, pre-defined quotas were used for age, gender, region, and housing status (owner/tenant) [36]. Participants were surveyed from April to May 2016. Out of 17,211 invitees, 7,044 participated in the survey, resulting in a participation rate of 40.93\%. 5,486 completed the survey (response rate $31.87 \%$ ), but 471 were screened out who were neither fully nor partly responsible for their household's expenses, resulting in an analytical sample of 5,015 (mean age $=46.19$, female $=50.87 \%$, mean household size $=2.25$; see Table A.1). The respondents chose among three languages to complete the survey, German $(n=3650)$, French ( $\mathrm{n}=1307)$, and English $(\mathrm{n}=58)$. 


\section{2. $\quad$ Measures}

\subsubsection{Outcome variables}

We analyzed washing and drying clothes and showering because these ECBs cover different core domains of household energy consumption (electricity and warm water) and are relevant to overall energy consumption. For example, in the European Union (EU), washing accounted for $6.4 \%$ of annual household electricity consumption in 2007 [37]. Together, the washing and drying proportion of total household electricity consumption was $16 \%$ in 12 European countries [38,39] —a similar share was estimated for Switzerland [40]. Warm water is mainly consumed for personal hygiene (showering and taking a bath) [41]. Since $62.5 \%$ of the people we surveyed do not take baths, we focused on showering, which is also the most practiced form of washing the body in other countries (for the United Kingdom (UK), see [7]).

To operationalize washing and drying clothes, participants were asked how many times per week on average they use a washing machine and/or tumble dryer. The question was presented only to respondents who had previously stated that they had a washing máchine (70.3\%) or a tumble dryer (48.8\%) for private use in their household. ${ }^{1}$ Respondents could enter any value between zero and 40 , using two decimals. The average number of wash cycles per week and household was $2.82(\mathrm{SD}=2.24, \min =0, \max =31, \mathrm{n}=3526)$, and the average number of drying cycles per week and household was $1.90(\mathrm{SD}=1.96, \mathrm{~min}=0$, $\max =22, \mathrm{n}=2446)$. For showering, participants were asked how many showers were taken, on average, in their household per week $(\mathrm{M}=9.79, \mathrm{SD}=6.48$, $\min =0, \max =90, \mathrm{n}=5009)$.

The observed 30 zero values for using the washing machine and 327 zero values for the tumble dryer could mean a) that the washing machine/tumble dryer was broken, or b) that respondents hand washed/line dried their clothes, or c) that another person in the household did the laundry. We tested for systematic differences by comparing the means or proportions of some key features (e.g., household size, education, age, gender, and practicespecific want) between respondents who indicated zero washing or drying cycles and the rest of the model sample. For washing clothes, respondents who stated zero wash cycles were, on average, older $(p<0.01)$ and lived in smaller households $(p<0.001)$ than the rest of the model sample. For drying clothes, those who indicated a zero value lived in smaller households $(p<0.001)$, found it less important to wear fresh clothes every day $(p<0.001)$, and were more likely female $(p<0.01)$. For showering, we observed 46 zero values, but if baths taken per week and household were added, only three zero values remained (i.e., in 43 households, no showers are taken, only baths). These three remaining zeros are probably typos, as a look at the data did not reveal any irregularities. We kept all observations for the analysis (see Table A.1).

\subsubsection{Explanatory variables}

The meaning element of practice: norms, values, and wants

Norms were measured using four items rated with a five-point scale ranging from 1 ("completely disagree") to 5 ("completely agree"). ${ }^{2}$ The injunctive norm was measured using two items ("The members in my household expect that I save energy" and "Most of my acquaintances expect that I save energy"). The two items correlated with $r=0.56$. An index was calculated as the mean of the two items $(\mathrm{M}=2.79, \mathrm{SD}=1.03)$. Descriptive norms were measured using the item "I believe that most of my acquaintances save energy

\footnotetext{
${ }^{1}$ A 2015 consumer study in Switzerland and Liechtenstein found similar figures, namely that $68.8 \%$ of households had a personal washing machine/tumble dryer [42].

${ }^{2}$ The labeling of extreme points was slightly different in the English version (from "totally disagree" to “totally agree”).
} 
whenever possible" $(\mathrm{M}=2.95, \mathrm{SD}=0.95)$. Personal norms were assessed using the item "I feel personally obliged to save as much energy as possible" $(\mathrm{M}=3.66, \mathrm{SD}=1.02)$.

To measure values, we employed an item battery developed by Steg et al. [28]. Respondents were asked to rate the importance of 16 values as guiding principles in their life (see Table A.2). The rating scale ranged from 1 ("not important") to 5 ("extremely important"). A confirmatory factor analysis assessed how well these items measured the four value orientations [43]. A root mean squared error of approximation of 0.059 and a standardized root mean squared residual of 0.055 suggested a good model fit [43] (see Table A.2). The indicators of the respective value dimensions were added, and the mean was calculated. This calculation resulted in four value orientation indices: altruistic $(\mathrm{M}=4.03, \mathrm{SD}=0.67)$, biospheric $(\mathrm{M}=4.10, \mathrm{SD}=0.69)$, egoistic $(\mathrm{M}=2.79, \mathrm{SD}=0.71)$, and hedonic $(\mathrm{M}=3.79$, $\mathrm{SD}=0.74)$.

To assess practice-specific wants, respondents were asked, "How important is the following to you?” Respondents could indicate the importance of each item with a scale ranging from 1 ("not at all important") to 5 ("very important"). ${ }^{3}$ From that list, one item was used for each model- "wear fresh clothes every day" $(\mathrm{M}=2.70, \mathrm{SD}=1.25)$ for the washing and drying model and "take long showers" $(\mathrm{M}=2.36, \mathrm{SD}=1.13)$ for the showering model.

The competence element of practice: knowledge and self-efficacy

For factual knowledge, people were asked to indicate whether the statements displayed in Table 1, most of which have been considered facts in previous research on knowledge, were true or false or whether they did not know [25,30,44]. A factual knowledge scale was created by summing up the correct answers $(\mathrm{M}=2.68, \mathrm{SD}=1.05)$. For self-efficacy, we used one item representing efficacy expectation ("I know how to behave in an environmentally friendly way") with a scale ranging from 1 ("completely disagree") to 5 ("completely agree"; $\mathrm{M}=4.01, \mathrm{SD}=0.80$ ).

Table 1

Factual knowledge items.

Item

$\%$ of respondents who gave the correct answer

KN1. The biggest proportion of energy consumed in a

Swiss household is for heating purposes.

$\mathrm{KN} 2 . \mathrm{CO}_{2}$ emissions play a crucial role in global warming.

KN3. Coal is a renewable energy resource.

KN4. Hydroelectric power plants account for $10 \%$ of the total Swiss electricity production.

38.80

Note: N=5015. Correct answers are KN1: “true,” KN2: “true,” KN3: “false,” and KN4: “false.”

The material element of practice

In the model assessing showering practices, the number of bathrooms and toilets (i.e., bathrooms without a tub/shower) per household was assessed $(M=1.70, S D=0.70$, Min=0,

\footnotetext{
${ }^{3}$ The scales for five-category variables were not labeled identically across item batteries. The scale for assessing values ranged from "not important" to "extremely important." This labeling relates to the literature on measurement of values [26,28]. Practice-specific wants were measured on a scale ranging from "not at all important” to "very important." This difference might have caused confusion among respondents, although the questions were placed in different sections of the questionnaire.
} 
Max=5, N=5015) with the question "Your accommodation contains ... bathrooms, toilets," with a scale ranging from " 0 " to " 5 or more."

\section{Socio-demographic characteristics}

Relevant socio-demographic variables were chosen according to previous research $[8,45,46]$. Descriptive statistics for age, gender, region, housing status, household income, and household size are shown in Table A.1. Furthermore, years of education ( $M=13.77$, $\mathrm{SD}=1.93$, Min=7, Max=16, $\mathrm{N}=5012$ ) were included in the analysis, as well as location (2,594 lived in urban areas, 1,358 in suburbs, and 1,060 in rural areas; $\mathrm{N}=5012$ ). Additionally, we included a dummy variable for children in the household (1508=yes; $3507=$ no). To account for non-linearity, we added quadratic terms for household size and age.

\subsection{Data analysis}

\subsubsection{Regression model}

To examine the association of the key research variables with washing, drying, and showering, we fitted ordinary least squares (OLS) regression models to the data. ${ }^{4} \mathrm{We}$ observed outliers in the dependent variables, which are indicated by high maximum values of washing, drying, and showering frequencies (see sub-section 3.2.1). OLS regression is sensitive to extreme outliers. Thus, we log-transformed the outcome variable after adding one to all values. We added one to $Y_{i}$ because $\ln (0)$ is undefined. For each of the three dependent variables, we estimated a separate model using the following regression equation:

$$
\ln \left(Y_{i}+1\right)=\alpha+\beta_{k} X_{i k}+\varepsilon_{i}, i=1, \ldots, n, \text { and } k=1, \ldots, k .
$$

$Y_{i}$ is the respective dependent variable (i.e., in Model 1 , the number of wash cycles per week; in Model 2, the number of drying cycles per week; and in Model 3, the number of showers per week and household). $\alpha$ is a constant, $\beta_{k}$ are the parameters we want to estimate, $X_{i k}$ are the explanatory variables in the respective model (see sub-section 3.2.2. and Table 2), and $\varepsilon_{i}$ is the error term.

To facilitate the interpretation of the models using the log-transformed average washing, drying, and showering frequencies, we re-calculated the estimates in the original metric. For example, with this re-transformation, for $k=1$, the results can be interpreted as a oneunit change in $x_{1}$, which is associated with a change in $\hat{y}$ of $\widehat{\beta_{1}}$, while all other variables are set to their mean. We faced no problem with multicollinearity - the mean variance inflation factor was 1.35 for the washing clothes model, 1.37 for the drying clothes model, and 1.36 for the showering model (Table B.1 shows the correlation coefficients for all explanatory variables). To avoid omitted variable bias, we included the number of wash cycles as an independent variable in the drying model (because washing clothes is a pre-condition for drying them). Thereby, we excluded 11 respondents who had a tumble dryer for private use but not a washing machine. All analyses were performed using Stata version 14.2; the regression table and correlation matrix were produced by employing the estout package $[47,48]$.

\subsubsection{Selection model}

\footnotetext{
${ }^{4}$ The respondents indicated the average washing, drying, and showering frequencies using decimals. Thus, these variables may not be considered count data, and we could not estimate count data models. Nevertheless, we compared OLS regressions to negative binomial regression models. The negative binomial regression models fit the data less well than did the OLS regression, as indicated by a higher Akaike information criterion value.
} 
The dependent variable for the washing and drying practice was observed only for those who own a washing machine/tumble dryer for private use. Those observations may be biased by a selection effect because having a washing machine or tumble dryer for private use is more frequent among certain socio-demographic groups than others. Therefore, we estimated a Heckman selection model. This model assumes that there is an underlying regression relationship (regression equation),

$$
y_{i}=x_{j} \beta+u_{1 i} .
$$

The dependent variable is observed for observation $j$ (selection equation), if

$$
z_{j} \gamma+u_{2 i}>0 .
$$

With $u_{1} \sim N(0, \sigma), u_{2} \sim N(0,1)$, and $\operatorname{corr}\left(u_{1}, u_{2}\right)=p$. When $p \neq 0$, standard regression techniques applied to equation 2 yield biased results.

We estimated the Heckman selection model separately for washing and drying practices. In the selection equation (3), all independent variables listed in Table 2 (including owner) were regressed on having a washing machine/tumble dryer for private use employing a probit model. In the second step, all independent variables listed in Table 2 (excluding the owner variable) were regressed on number of wash/dry cycles per week, employing our original regression equation (1).

For washing, the error terms in the selection (i.e., having a washing machine for private use) and regression equations (i.e., number of wash cycles per week) were correlated. Thus, we estimated wash cycles per week with the Heckman selection model with the two-step estimator. For the drying model, the error term in the selection and regression equations were not correlated. Consequently, we did not employ the two-step estimator. As an implication, our results for drying clothes are not representative of the full Swiss population (see Table A.1).

\section{4. $\quad$ Results}

Table 2 presents the regression results. The three columns show the re-transformed estimates that can be interpreted in the same way as in the OLS regression on the untransformed outcome variable.

Table 2

\begin{tabular}{|c|c|c|c|}
\hline \multirow{3}{*}{ Injunctive norm } & \multirow{2}{*}{$\begin{array}{c}\text { Model } 1^{a} \\
\text { Number of wash } \\
\text { cycles per week }\end{array}$} & \multirow{2}{*}{$\begin{array}{c}\text { Model } 2 \\
\begin{array}{l}\text { Number of drying } \\
\text { cycles per week }\end{array}\end{array}$} & \multirow{2}{*}{$\begin{array}{c}\text { Model } 3 \\
\text { Number of } \\
\text { showers per week } \\
\text { and household }\end{array}$} \\
\hline & & & \\
\hline & $-0.041 \quad(0.028)$ & $-0.024 \quad(0.026)$ & $0.009 \quad(0.077)$ \\
\hline Descriptive norm & $-0.034 \quad(0.028)$ & $0.003 \quad(0.026)$ & $-0.020 \quad(0.078)$ \\
\hline Personal norm & $-0.015 \quad(0.029)$ & $-0.055^{*} \quad(0.026)$ & $0.112 \quad(0.080)$ \\
\hline Hedonic values & $0.030 \quad(0.037)$ & $-0.002 \quad(0.035)$ & $0.532^{* * *} \quad(0.103)$ \\
\hline Altruistic values & $-0.018 \quad(0.044)$ & $0.002 \quad(0.040)$ & $0.232 \quad(0.122)$ \\
\hline
\end{tabular}

Regression results. 


\begin{tabular}{|c|c|c|c|}
\hline Biospheric values & $-0.038 \quad(0.047)$ & $0.011 \quad(0.043)$ & $-0.325^{*} \quad(0.131)$ \\
\hline Egoistic values & $0.010 \quad(0.037)$ & $0.073^{*} \quad(0.034)$ & $-0.217^{*} \quad(0.100)$ \\
\hline Want: fresh clothes & $0.131^{* * *} \quad(0.020)$ & $0.051^{* *} \quad(0.018)$ & \\
\hline Want: long showers & & & $0.433^{* * *} \quad(0.061)$ \\
\hline Factual knowledge & $0.030 \quad(0.024)$ & $-0.019 \quad(0.023)$ & $0.075 \quad(0.067)$ \\
\hline Self-efficacy & $0.062 \quad(0.033)$ & $0.009 \quad(0.030)$ & $-0.080 \quad(0.091)$ \\
\hline $\begin{array}{l}\text { Number of wash cycles } \\
\text { per week }\end{array}$ & & $0.320^{* * *} \quad(0.011)$ & \\
\hline Number of bathrooms & & & $(0.113)$ \\
\hline \multicolumn{4}{|c|}{$\begin{array}{l}\text { Income (gross household income per month in CHF; } \\
\text { reference category: 6000-8999) }\end{array}$} \\
\hline 3000 or less & $-0.191 \quad(0.137)$ & $-0.146 \quad(0.139)$ & $-0.804^{* *} \quad(0.293)$ \\
\hline $3000-4459$ & $-0.115 \quad(0.100)$ & $(0.102)$ & $-0.676^{* *} \quad(0.244)$ \\
\hline 4500-5999 & $-0.110 \quad(0.082)$ & $0.074 \quad(0.078)$ & $-0.522^{*} \quad(0.209)$ \\
\hline $9000-12000$ & 0.078 & $0.187^{* *} \quad(0.062)$ & $0.790^{* * *} \quad(0.203)$ \\
\hline 12000 or more & $0.115(0.080)$ & $0.184^{* *} \quad(0.067)$ & $1.293^{* * *} \quad(0.245)$ \\
\hline Income not indicated & $20 \quad(0.079)$ & $0.221^{* *} \quad(0.073)$ & $0.473^{*} \quad(0.225)$ \\
\hline Household size (HHS) & $0.836^{* * *} \quad(0.082)$ & $0.183^{*} \quad(0.075)$ & $3.633^{* * *} \quad(0.232)$ \\
\hline $\mathrm{HHS}^{2}$ & $-0.052^{* * *} \quad(0.011)$ & $-0.020^{*} \quad(0.010)$ & $-0.259^{* * *}(0.033)$ \\
\hline $\begin{array}{l}\text { Children in household } \\
\text { (reference category: no } \\
\text { child in household) }\end{array}$ & $0.260^{* *} \quad(0.084)$ & $0.107 \quad(0.075)$ & $-1.219^{* * *}(0.222)$ \\
\hline $\begin{array}{l}\text { Owner (reference } \\
\text { category: tenant) }\end{array}$ & & $-0.010 \quad(0.051)$ & $-0.129 \quad(0.167)$ \\
\hline Education (in years) & $-0.002 \quad(0.013)$ & $-0.004 \quad(0.012)$ & $-0.017 \quad(0.036)$ \\
\hline Age & $0.026^{*} \quad(0.010)$ & $0.005 \quad(0.010)$ & $0.137^{* * *} \quad(0.030)$ \\
\hline Age $^{2}$ & $-0.000^{* *} \quad(0.000)$ & $-0.000 \quad(0.000)$ & $-0.002^{* * *}(0.000)$ \\
\hline
\end{tabular}




\begin{tabular}{|c|c|c|c|c|}
\hline $\begin{array}{l}\text { Female (reference } \\
\text { category: male) }\end{array}$ & $0.138^{* *}$ & $(0.052)$ & $-0.219^{* * *} \quad(0.048)$ & $0.122 \quad(0.143)$ \\
\hline $\begin{array}{l}\text { French-speaking region } \\
\text { (reference category: } \\
\text { German-speaking region) }\end{array}$ & -0.034 & $(0.059)$ & $0.236^{* * *} \quad(0.060)$ & $1.059^{* * *} \quad(0.172)$ \\
\hline \multicolumn{5}{|c|}{ Location (reference category: urban) } \\
\hline Suburbs & 0.043 & $(0.061)$ & $0.085 \quad(0.051)$ & $0.139 \quad(0.163)$ \\
\hline Rural & 0.036 & $(0.068)$ & $0.099 \quad(0.056)$ & $-0.304 \quad(0.172)$ \\
\hline$N$ & 4916 & & 2385 & 4910 \\
\hline Adj. $R^{2}$ & & & 0.415 & 0.304 \\
\hline \multicolumn{5}{|c|}{$\begin{array}{l}\text { Standard errors in parentheses } \\
{ }^{*} p<0.05,{ }^{* *} p<0.01,{ }^{* * *} p<0.001 \\
a \text {. Model } 1 \text { estimates are from a Heckman selection model (two-step). }\end{array}$} \\
\hline
\end{tabular}

Wanting to wear fresh clothes every day was positively associated with the number of wash cycles per week (Table 2, Model 1). Hypothesis H1a is supported. The social-psychological variables used to operationalize the meaning and competence elements of the SPT framework were not statistically significant. ${ }^{5}$ The quadratic term for household size was statistically significant and negative, indicating that wash cycles do not linearly increase with household size. For example, increasing household size from two to three was associated with a 0.63 increase in wash cycles per week, but increasing household size from four to five was associated with a 0.42 increase in wash cycles per week. Having at least one child in the household was associated with 0.26 more wash cycles. Being female was associated with 0.14 more wash cycles.

\section{2. $\quad$ Drying}

Egoistic value orientation and the desire to wear fresh clothes every day were positively associated with tumble dryer usage (Table 2, Model 2), lending support for hypothesis H1b. Of the other variables used to inform the meaning element of practice, personal norms were negatively associated with dryer usage. ${ }^{6}$ The number of wash cycles had the highest effect size (0.32). The linear term for household size was positive and the quadratic term negative, indicating that the number of drying cycles levels off with increasing household size. Higher-than-average household income was associated with 0.18 to 0.19 more drying cycles per week. Being female was associated with 0.22 fewer drying cycles. Living in the French-speaking region was associated with 0.24 more drying cycles.

\subsection{Showering}

Hedonic value orientation and the importance of taking long showers were positively related to the number of showers per week and per household (Table 2, Model 3). This provided supported for hypothesis H1c. Egoistic value orientation was negatively associated with the number of showers per week and per household, as was biospheric value

\footnotetext{
${ }^{5}$ However, in an alternative model, where we used washing per person and week as the dependent variable (i.e., we divided the number of washing cycles by household size and did not include household size as explanatory variable), the injunctive norm variable was significantly negatively associated with washing cycles per week $\widehat{(\beta}=-0.035(p<0.05))$.

${ }^{6}$ In an alternative model, where we used drying cycles per person and week as the dependent variable the injunctive norm variable was significantly negatively associated with drying cycles per week $\widehat{(\beta}=$ $-0.027(p<0.05))$
} 
orientation. One additional bathroom was associated with 0.38 more showers per week and per household. Hypothesis H2 was supported. The largest effects were found for sociodemographic characteristics. The linear terms for household size and age were positive and the quadratic terms negative, indicating that the number of showers taken levels off with increasing household size and age. Having at least one child in the household was associated with 1.22 fewer showers per week. Higher-than-average household income was associated with 0.79 to 1.29 more showers per week. Living in the French-speaking region was associated with 1.06 more showers per week.

\section{Discussion}

\section{1. $\quad$ The meaning element of practice: norms, values, and wants}

Previous research has shown that individual differences in tumble dryer usage relate to norms - what people think of as "easy" and "necessary" [5]. The present analysis revealed a negative association between personal norms and number of drying cycles. People who feel personally obliged to save energy used a tumble dryer less often. However, the effect size was small. Injunctive and descriptive norms were not found to explain differences in the three routinized ECBs.

Egoistic value orientation was positively associated with drying cycles. This finding is in line with environmental psychology theorizing that egoistic value orientation is positively associated with resource-intense behaviors [28]. Hedonic values were positively associated with the number of showers per week. If we assume frequent showering reflects high energy use, then the results are in line with Steg et al. [28] who found a positive association between hedonic values and energy consumption. Furthermore, the negative association between biospheric values and showering frequency is in line with environmental psychology findings. However, the negative association between egoistic value orientation and showering contradicts environmental psychology theory. Of course, the mere number of showers per week provides only an approximation of energy consumption associated with that practice. Water temperature and showering length also play important roles. Thus, the data may not be fine-grained enough to test the link between value orientation and resource consumption. Nevertheless, an association among pleasure, comfort (i.e., hedonic value orientation), and the practice of showering seems plausible and was revealed by the analysis.

Practice-specific wants explained differences in all three routinized ECBs; hypotheses H1a through H1c were supported. The want to take long showers was positively associated with the number of showers. This finding could be related to warm water use, and thus, resource consumption, as people most likely perceive long warm showers as pleasant. This finding is in line with Browne et al. [7], who found a positive relationship between showering frequency and length for their "attentive cleaners" cluster. Regarding washing and drying clothes, the present analysis revealed that people who find wearing fresh clothes every day important, on average, wash and dry their clothing more often. Thus, the relationship between wants and actual behavior is evident. This result indicates a high clothing turnover, which was also found by Gram-Hanssen [5]; some of the interviewees perceived that once clothes were worn, they must be washed before being hung up again in the closet.

\subsection{The competence element of practice: knowledge and self-efficacy}

Factual knowledge and self-efficacy, which we associated with the competence element of practice, did not explain differences among the three routinized ECBs. One explanation can be found in Gram-Hanssen's [5] study. The author showed that people rarely link the environment (and thus, environmental self-efficacy and energy-related knowledge) to usage frequency of the washing machine. In her study, interviewees instead linked the wash cycle 
temperature or the degree the machine is filled to environmental issues. Thus, the present findings contribute to the literature, showing that factual knowledge is generally less important in the usage or performance frequency of everyday life behavior. We also found that the degree to which individuals perceive themselves as knowing how to behave environmental friendly (i.e., an environmental efficacy expectation) does not explain variations in the performance of the three routinized ECBs.

\subsection{The material element of practice}

In this study, the materials related to laundry practice were the washing machine and the tumble dryer. Only people with a washing machine and/or a tumble dryer in their household for private use were asked how often they wash and dry clothes. Being an apartment owner or homeowner was the strongest predictor of having a washing machine for private use; since renting an apartment in a building with shared access to washing machines and tumble dryers is common in Switzerland, washing machine ownership is relatively low compared to other European countries (for the UK, see [4]). We estimated washing frequency with a Heckman selection model to account for selection bias.

We included washing as an independent variable in the drying model. People use methods other than the tumble dryer to dry their clothes (e.g., line drying). Although the data set did not include more materials related to the laundry practice, the results revealed that such materials for drying clothes exist.

Regarding showering practice, materials had a significant association with the number of showers. Materials were operationalized as additional bathrooms/toilets that may provide the opportunity to install an additional shower. A bathroom may also present an additional location to engage in non-showering bathroom activities irrespective of whether there is an additional shower, resulting in less crowding. This result supported hypothesis H2 and shows the benefit of considering materials when analyzing routinized ECBs.

\subsection{Socio-demographic characteristics}

The number of wash and drying cycles, as well as showers, per week were measured on the household level. Therefore, it is not surprising that the control variable for household size had a strong effect on the ECBs. The analysis further revealed that the relationship between household size and frequency in routinized ECB performance is not linear.

Income had a relatively large effect on the frequency and the possibilities of washing, ${ }^{7}$ drying, and showering. Bourdieu [49] believed classes can be separated into "sets of agents who [...] have every likelihood of having similar dispositions and interests and therefore of producing similar practices” (p. 198); in other words, people in the same economic class likely behave in similar ways [50]. Our empirical findings support this postulation and suggest that socio-economic status plays a huge role in explaining variations in routinized ECB performance.

Region (French- and German-speaking regions of Switzerland), gender, and age explained variations in at least two of the three routinized ECBs. Previous studies showed that living in the French-speaking region of Switzerland is associated with lower housing emissions [45]. However, looking at specific practices reveals that, on average, people in the Frenchspeaking region shower and use a tumble dryer more often than people in the Germanspeaking region. These variations are likely related to cultural differences, including different understandings of appropriate personal hygiene and the "normal” way of doing laundry. Regarding gender differences, the analysis revealed that women, on average, wash their clothes more frequently but tumble dry less. There are different possible explanations

\footnotetext{
${ }^{7}$ In the selection equation for washing, income was a significant predictor of having a washing machine for private use.
} 
for this variation. First, it might be that understandings of appropriate laundering differ between men and women, such as how fast the laundry should be done and how clothes should feel after washing (i.e., the tumble dryer is used by some people just because it softens clothes [5]). Second, differences in the performance of the drying practice may relate to different materials used for male and female clothing [5]. Women's clothes are often finer; therefore, women might not use the tumble dryer for these types of clothes because it may spoil them. Third, different frequencies of tumble dryer usage may indicate different opportunity costs of men and women. Generally, Gram-Hanssen [5] has found that people give very different explanations for their usage or non-usage of a tumble dryer. Our analysis provides an insight into which factors can explain this variation in performance of the drying practice (i.e., regional factors and gender). Variations in routinized ECBs explained by age can be related to Browne et al. [7] who found that practices can change through life events, such as retirement. Their cluster analysis showed that "low frequent showerers" are older than average and retired, which is confirmed by our findings.

In summary, our analysis revealed that socio-demographic predictors play an important role in explaining variations in routinized ECB performance. Furthermore, former empirical research based on SPT found variations in the performance of practices due to age [7] and gender [5]. However, there is potential to further theorize the role of socio-demographic factors in current SPT versions as well as in social psychology. A starting point might be offered by the concept of classes by Bourdieu [49].

\subsection{Limitations}

First, the question how often people wash and dry their clothes was shown only to respondents who have access to a washing machine and/or a tumble dryer for private use. We evaluated a potential selection bias by employing a Heckman selection model. For drying, the error terms in the selection equation and the regression equation were not correlated; thus, we did not estimate a selection model for drying. Our results for drying clothes can therefore not be regarded as representative of the entire Swiss population, but only of the sub-population of those people having a tumble dryer for private use (see Table A.1).

Second, some of the one-item measures might not adequately capture the practices studied. Furthermore, these measures do not help estimate energy consumption associated with the performance of specific routinized ECBs. For example, we did not have information on the wash temperature, the degree to which the machine was filled, or the shower length. Still, two trends in washing clothes (increased frequency and lower temperatures), which were identified by Shove [4], may outweigh one another in terms of electricity consumption.

Third, assessing the outcome variable for washing and drying clothes ${ }^{8}$ and showering at the household level, while associating these practices with individually perceived meanings and competences, entails certain limitations. Nevertheless, the values explained the differences, although the outcome was measured at the household level. The same holds for practice-specific wants that were assessed at the individual level. Similarly, other researchers [45,51] have measured behaviors on the household level, but using environmental concern as the independent variable on the individual level. The explanatory power of individual attributes for usage and performance frequency at the household level might indicate that households can be viewed as "sociocultural units" [52] with shared

\footnotetext{
${ }^{8}$ Washing and drying clothes can be considered household behavior if the laundry is done for the household (and people do not do their laundry separately). However, the question was formulated as "How often do you use ... 1) the washing machine, 2) the tumble dryer.” Therefore, respondents might have reported the number of times they personally used the washing machine/tumble dryer and might not have considered the frequency with which their household washed and dried clothes.
} 
norms, values, and beliefs. The relevance of including household interactions when analyzing practices has also been articulated by Bartiaux and Salmon [53]. Future studies should shed light on interactions between household members and how these interactions shape norms, values, and wants.

Fourth, although the models revealed significant associations of some practice elements with ECBs, a few of the observed effects are small, especially in comparison to the estimates of socio-demographic characteristics. Although similar studies [45,51] have suggested that these effect sizes are within the bounds of expectations for ECBs, the results indicate a need to further elaborate operationalization strategies for the meaning, competence, and material elements of practice.

\subsection{Directions for future research}

Although an epistemologically and theoretically consistent integration of SPT and psychological approaches is beyond our scope, more theoretical work in this direction is clearly needed. With a focus on an SPT framework and the inclusion of variables that allow measurement of individual perceptions, we have accounted for individual (or sub-group, such as regional or gender) variations in the performance of practices. An interesting direction for future research may be to unpack the reasons behind these differences. Practice-specific wants explain differences in the three routinized ECBs. Thus, from an SPT perspective, analyzing how these personal wants evolve and change (on an individual level) by employing a longitudinal design would be worthwhile.

Furthermore, our research approach can be further developed to estimate the impact of certain routinized ECBs by including more information on their energy intensity (wash cycle length, temperature, etc.) and employing a longitudinal or experimental design. This would contribute to the social science research on quantifying ECBs and their changes, as was discussed in the April 2017 special issue of this journal (see e.g., Stern's contribution [54]).

Regarding the social-psychological predictors, other scholars have stated that specific attitudes may be better predictors than general environmental and energy-related attitudes [55]. Future studies can consider additional practice-specific norms, values, and competences, instead of general environmental and energy-related ones.

\section{Conclusion}

This study aimed to advance our understanding of routinized ECBs, such as washing and drying clothes and showering, by focusing on the association of individual and structural factors. Contributing to an emergent strand of research [9,13,20], we attempted to inform core elements of an SPT framework with concepts of social-psychological research. We developed an analytical framework where we integrated materials and practice-specific wants, which are infrequently considered in social-psychological models of routinized ECBs. Using recent data from a large-scale survey of households in Switzerland and employing regression analyses, we demonstrated the benefit of integrating elements of social psychology and SPT to understand routinized ECBs. The results suggest that individual value orientation, practice-specific wants and materials, as well as sociodemographic factors, explain differences in routinized ECB performance. These findings emphasize the advantage of considering individual and structural factors in analyzing routinized ECBs. This paper demonstrates an empirical attempt to unleash the potential of the rich theoretical insights afforded by SPT and psychology-based ECB determinants. However, further research is needed to integrate SPT and psychological approaches in a more consistent way. In addition to our scientific contributions, considering individual and structural factors may help define more successful instruments for routinized ECBs. 


\section{Acknowledgments}

This research was conducted as XXXXX funded by the Mercator Foundation Switzerland [project number $X X X X X X]$. The paper is also part of the activities of SCCER CREST, which is financially supported by Innosuisse, the Swiss Innovation Agency. The study benefited substantially from access to the SHEDS dataset. We thank our anonymous reviewers whose comments and suggestions helped improve and clarify this paper. 


\section{Appendix A.}

Table A.1.

Descriptive statistics for selected socio-demographic indicators ${ }^{1}$

\begin{tabular}{lccccc}
\hline & $(1)$ & $(2)$ & $(3)$ & $(4)$ & $(5)$ \\
\hline & $\begin{array}{c}\text { Population } \\
\text { characteristics }\end{array}$ & $\begin{array}{c}\text { Total } \\
\text { sample }\end{array}$ & $\begin{array}{c}\text { Washing } \\
\text { model }\end{array}$ & $\begin{array}{c}\text { Drying } \\
\text { model }\end{array}$ & $\begin{array}{c}\text { Showering } \\
\text { model }\end{array}$ \\
\hline Age (mean) & 41.99 & 46.19 & 46.33 & 47.53 & 46.33 \\
$\begin{array}{l}\text { Gender (\% female) } \\
\begin{array}{l}\text { Region (\% French- } \\
\text { speaking region) }\end{array}\end{array}$ & 50.42 & 50.87 & 50.53 & 45.24 & 50.55 \\
$\begin{array}{l}\text { Housing status } \\
\text { (\% owner) }\end{array}$ & 25.48 & 24.79 & 24.76 & 22.43 & 24.73 \\
$\begin{array}{l}\text { Income (median } \\
\text { category, CHF) }\end{array}$ & 38.40 & 37.53 & 37.71 & 52.91 & 37.72 \\
Household size & $6957^{4}$ & $6000-$ & $6000-$ & $9000-$ & $6000-$ \\
$\mathrm{N}$ & 2.25 & 8999 & 8999 & 12000 & 8999 \\
& 8418000 & 5015 & 4916 & 2385 & 4910 \\
\hline
\end{tabular}

${ }^{1}$ Comparison of the model samples (columns 2-5) to official statistics (column 1). The differences in $\mathrm{N}$ in columns 2 to 5 are due to missing cases and sub-sample selection criteria (see sub-section 3.2 on outcome measures).

${ }^{2}$ For official figures, refer to the Federal Statistical Office [56-61].

${ }^{3}$ To calculate the median income category, respondents who did not wish to indicate their income were excluded. These were 648 in the total sample and washing model, 335 in the drying, and 647 in the showering model. But all these were taken into consideration in our regression model ("income not indicated", see Table 2). 96 cases with unknown household income were treated as missing values.

${ }^{4}$ Mean disposable income [60] 
Table A.2.

Standardized results of confirmatory factor analysis for value items, loadings, and standardized error variances

\begin{tabular}{|c|c|c|c|c|}
\hline Latent constructs and items & $\begin{array}{l}\text { Factor } \\
\text { loading }\end{array}$ & $\begin{array}{l}\text { Standard } \\
\text { error }\end{array}$ & $\begin{array}{c}\text { Error } \\
\text { variance }\end{array}$ & $\begin{array}{l}\text { Standard } \\
\text { error }\end{array}$ \\
\hline \multicolumn{5}{|l|}{ Hedonic } \\
\hline Pleasure: joy, gratification of desires & .808 & .010 & .347 & .016 \\
\hline Enjoying life: enjoying food, sex, leisure & .745 & .010 & .446 & .015 \\
\hline Self-indulgent: doing pleasant things & .591 & .012 & .650 & .014 \\
\hline \multicolumn{5}{|l|}{ Altruistic } \\
\hline Equality: equal opportunity for all & .704 & .010 & 504 & .013 \\
\hline A world at peace: free of war and conflict & .665 & .010 & & .014 \\
\hline $\begin{array}{l}\text { Social justice: correcting injustice, care for the } \\
\text { weak }\end{array}$ & .733 & 09 & & .014 \\
\hline Helpful: working for the welfare of others & .512 & & .738 & .013 \\
\hline \multicolumn{5}{|l|}{ Biospheric } \\
\hline $\begin{array}{l}\text { Respecting the earth: harmony with other } \\
\text { species }\end{array}$ & & & .404 & .011 \\
\hline Unity with nature: fitting into nature & & .008 & .445 & .011 \\
\hline Protecting the environment: preserving nature & & .006 & .316 & .010 \\
\hline $\begin{array}{l}\text { Preventing pollution: protecting natural } \\
\text { resources }\end{array}$ & & .007 & .385 & .011 \\
\hline \multicolumn{5}{|l|}{ Egoistic } \\
\hline Social power: control over others, dominance & .722 & .009 & .479 & .013 \\
\hline Ambitious: hard-working, aspiring & .571 & .012 & .674 & .013 \\
\hline Authority: the right to lead or command & .795 & .009 & .368 & .014 \\
\hline $\begin{array}{l}\text { Influential: having an impact on people and } \\
\text { events }\end{array}$ & .495 & .013 & .755 & .012 \\
\hline Wealth: material possessions, money & .514 & .012 & .736 & .013 \\
\hline
\end{tabular}

$N=5015$ 
Appendix B.

Table B.1.

Correlation table of all explanatory variables.

\begin{tabular}{|c|c|c|c|c|c|c|c|c|c|c|c|c|c|c|c|c|c|c|c|c|c|c|c|c|c|c|}
\hline & 1 & 2 & 3 & 4 & 5 & 6 & 7 & 8 & 9 & 10 & 11 & 12 & 13 & 14 & 15 & 16 & 17 & 18 & 19 & 20 & 21 & 22 & 23 & 24 & 25 & 26 \\
\hline $\begin{array}{l}1 \text { Injunctive } \\
\text { norm }\end{array}$ & 1.000 & & & & & & & & & & & & & & & & & & & & & & & & & \\
\hline 2 Descriptive & $0.422^{* w *}$ & 1.000 & & & & & & & & & & & & & & & & & & & & & & & & \\
\hline 3 Personal & $0.423^{m+*}$ & $0.315^{* * * *}$ & 1.000 & & & & & & & & & & & & & & & & & & & & & & & \\
\hline $\begin{array}{l}\text { nomm } \\
4 \text { Self- }\end{array}$ & $0.196^{* \ldots+\cdots}$ & $0.146^{* * *}$ & $0.323^{* * *}$ & 1.000 & & & & & & & & & & & & & & & & & & & & & & \\
\hline $\begin{array}{l}\text { efficacy } \\
5 \text { Factual }\end{array}$ & $0.048^{+\ldots+*}$ & $-0.033^{*}$ & $0.069^{* * *}$ & $0.154^{* * *}$ & 1.000 & & & & & & & & & & & & & & & & & & & & & \\
\hline $\begin{array}{l}\text { knowledge } \\
6 \text { Hedonic }\end{array}$ & $0.045^{* *}$ & $0.030^{*}$ & 0.001 & $0.083^{* * *}$ & $-0.048^{*+*+}$ & 1.000 & & & & & & & & & & & & & & & & & & & & \\
\hline $\begin{array}{l}\text { values } \\
7 \text { Altruistic }\end{array}$ & $0.222^{* * *}$ & $0.202^{+* *}$ & $0.328^{* * *}$ & $0.250^{-* * *}$ & 0.020 & $0.163^{* *}$ & 1.000 & & & & & & & & & & & & & & & & & & & \\
\hline $\begin{array}{l}\text { values } \\
8 \text { Biospheric }\end{array}$ & $0.276^{* * *}$ & $0.210^{* * *}$ & $0.475^{* * *}$ & $0.381^{* * *}$ & $0.052^{2 * *}$ & $0.151^{* * *}$ & $0.576^{6 * *}$ & 1.000 & & & & & & & & & & & & & & & & & & \\
\hline $\begin{array}{l}\text { values } \\
9 \text { Egosistic }\end{array}$ & $0.157^{*+*}$ & $0.137^{+* *+}$ & $0.028^{*}$ & 0.015 & -0.022 & $0.289^{* \cdots *}$ & -0.026 & -0.018 & 1.000 & & & & & & & & & & & & & & & & & \\
\hline $\begin{array}{l}\text { values } \\
10 \text { Fresh }\end{array}$ & 0.004 & $0.044^{* *+}$ & $-0.094^{4+*+}$ & $-0.102^{* * * *}$ & $-0.137^{+* a t}$ & $0.178^{* * *}$ & -0.016 & $-0.067^{*+*+*}$ & $0.211^{\prime *}$ & 1.000 & & & & & & & & & & & & & & & & \\
\hline 11 & 0.023 & -0.004 & 0.022 & $0.031^{*}$ & $0.070^{* * * *}$ & -0.025 & $-0.044^{* *}$ & -0.003 & $0.076^{+* *}$ & 0.013 & 1.000 & & & & & & & & & & & & & & & \\
\hline $\begin{array}{l}\text { Bathrooms } \\
12 \text { Long } \\
\text { chowers }\end{array}$ & $-0.044^{4^{*}}$ & $-0.061^{+*+*}$ & $-0.177^{4 * * *}$ & $-0.129^{+*+*}$ & -0.027 & $0.143^{+* * *}$ & $-0.126^{*+* *}$ & $-0.201^{+*+*}$ & $0.134^{+\ldots+*}$ & $0.223^{*+* *}$ & -0.022 & 1.000 & & & & & & & & & & & & & & \\
\hline $\begin{array}{l}\text { Showers } \\
13 \text { Income }\end{array}$ & $-0.032^{*}$ & 0.008 & $-0.039^{* * *}$ & $-0.038^{* *}$ & $-0.100^{*+*+t}$ & -0.027 & $-0.049^{*+* *}$ & $-0.042^{* * *}$ & $0.056^{* * *}$ & $0.075^{* * *}$ & $0.050^{4+* *+}$ & $0.031^{*}$ & 1.000 & & & & & & & & & & & & & \\
\hline 143000 or & 0.026 & 0.010 & 0.017 & 0.024 & $-0.049^{* * *}$ & -0.023 & $0.048^{* * * *}$ & $0.062^{* * * *}$ & $-0.056^{* *}$ & $-0.037^{* *}$ & $-0.150^{* * *}$ & -0.014 & -0.09 & 1.000 & & & & & & & & & & & & \\
\hline $\begin{array}{l}\text { less } \\
15\end{array}$ & $0.029^{*}$ & $0.070^{* * *}$ & $0.058^{* * *}$ & 0.025 & $-0.050^{*+*+*}$ & -0.021 & $0.050^{0+*}$ & $0.059^{*+* *+}$ & $-0.033^{*}$ & -0.027 & $-0.142^{*+*+*}$ & $-0.0411^{*}$ & 111 & $-0.071^{\ldots+\ldots}$ & 1.000 & & & & & & & & & & & \\
\hline 16 & -0.005 & $0.036^{*}$ & 0.028 & 0.005 & $-0.028^{*}$ & -0.009 & $0.050^{0+*}$ & 0.023 & $-0.040^{-* *}$ & -0.011 & $-0.169^{+\ldots+*}$ & 0.012 & $-0,15$ & $-0.093^{*+*}$ & $-0.122^{* * *}$ & 1.000 & & & & & & & & & & \\
\hline 17 & -0.019 & $-0.042^{* *}$ & $-0.034^{*}$ & -0.011 & $0.067^{7 \cdots *}$ & 0.015 & $-0.030^{*}$ & $-0.045^{* *}$ & 0.003 & -0.021 & $0.124^{+4+\cdots}$ & -0.008 & -0.196 & $-0.117^{*+* *}$ & $-0.154^{* * *}$ & $-0.201^{\prime * w}$ & 1.000 & & & & & & & & & \\
\hline $\begin{array}{l}9000-12000 \\
1812000 \text { or }\end{array}$ & -0.014 & $-0.062^{2 * * *}$ & $-0.031^{*}$ & 0.010 & $0.105^{5 * *}$ & $0.045^{* *+}$ & $-0.064^{*+*}$ & $-0.063^{* *+*}$ & $0.057^{7 * *}$ & 0.008 & 0.214 & $0.032^{*}$ & $-0.1566^{+*}$ & $-0.093^{*+*}$ & $-0.123^{3+4+\infty}$ & $-0.160^{+*+*}$ & $-0.202^{2 * *}$ & 1.000 & & & & & & & & \\
\hline $\begin{array}{l}\text { more } \\
19 \mathrm{HH} \text { size }\end{array}$ & $0.047^{+m+m}$ & $-0.041^{* *}$ & 0.015 & 0.005 & $0.060^{0 * *}$ & -0.012 & -0.012 & $-0.042^{2 *}$ & $0.055^{* * *}$ & -0.021 & $0.395^{+4}$ & -0.007 & 0.011 & $-0.152^{2+* *}$ & $-0.163^{*+*+}$ & $-0.168^{*+*}$ & $0.169^{+* *+}$ & $0.180^{+* * *}$ & 1.000 & & & & & & & \\
\hline 20 Owner & $0.070^{+5 . *}$ & $0.046^{* *}$ & $0.060^{0 * *}$ & $0.064^{* * * *}$ & $0.088^{9 * *}$ & $-0.090^{+\infty+*}$ & -0.015 & $0.053^{* * *}$ & $0.037^{* *}$ & $-0.051^{*}$ & $0.449^{\circ-5}$ & $-0.106^{* *}$ & 0.027 & -0.116 & $-0.081^{1+4+\infty}$ & $-0.095^{+* *+}$ & $0.072^{+* * *}$ & $0.110^{+3 * *}$ & $0.266^{+* *}$ & 1.000 & & & & & & \\
\hline 21 Education & 0.006 & $-0.070^{+* * *}$ & $-0.029^{*}$ & 0.027 & $0.170^{\circ+*}$ & 0.007 & $-0.051^{\ldots+*}$ & $-0.065^{5+* *}$ & 0.009 & $-0.060^{*}$ & $0.068^{84}$ & 0.026 & $-0.049^{+* *}$ & $-0.070^{+* * *}$ & $-0.115^{5+*}$ & -0.096 & $0.091^{+* t *}$ & $0.172^{+* * *}$ & $0.037^{*}$ & 0.001 & 1.000 & & & & & \\
\hline 22 Age & $0.092^{+* * *}$ & $0.141^{* * * *}$ & $0.116^{6+*}$ & $0.097^{* * * *}$ & $0.030^{*}$ & $-0.260^{* * * *}$ & $0.089^{9+*}$ & $0.180^{* * *}$ & $-0.062^{2 * *}$ & $-0.074^{*}$ & $0.153^{* * * *}$ & $-0.211^{1+*}$ & 0.001 & -0.008 & $0.075^{*+*}$ & $0.030^{*}$ & $-0.039^{* *}$ & $-0.075^{* * *}$ & $-0.127^{7+m}$ & $0.343^{* * * *}$ & $-0.152^{* * * *}$ & 1.000 & & & & \\
\hline 23 Female & -0.015 & $0.073^{* * * *}$ & $0.113^{2+\cdots}$ & 0.016 & $-0.265^{+* * *}$ & 0.005 & $0.195^{* * *}$ & $0.151^{* * *}$ & -0.143 & 0.007 & $-0.095^{*+*+}$ & $-0.050^{0 *}$ & $0.046^{6 *}$ & $0.055^{* * * *}$ & $0.080^{0 * *}$ & $0.078^{n+*}$ & $-0.080^{+* * *}$ & $-0.079^{+* *+}$ & $-0.117^{7+m}$ & $-0.098^{+\cdots+}$ & $-0.095^{+* * *}$ & $-0.095^{* * *}$ & 1.000 & & & \\
\hline 24 French & $0.159^{m+*}$ & $0.047^{* * *}$ & $-0.064^{*+* *}$ & $-0.077^{* * * *}$ & $-0.085^{*+*}$ & $0.239^{* * * *}$ & $0.076^{+\ldots+*}$ & $0.082^{*+*+}$ & 0.022 & $0.201^{*+*}$ & $0.031^{*}$ & 0.014 & -0.003 & 0.027 & 0.018 & -0.006 & 0.001 & $-0.031^{*}$ & $0.039^{+* *}$ & 0.004 & $0.031^{*}$ & $-0.056^{*+*}$ & 0.008 & 1.000 & & \\
\hline $\begin{array}{l}\text { Speaking } \\
25 \text { Suburbs }\end{array}$ & $-0.032^{*}$ & 0.003 & -0.027 & -0.014 & -0.011 & -0.023 & $-0.062^{2 *+*}$ & $-0.030^{*}$ & 0.020 & $0.028^{*}$ & $0.143^{3 * *}$ & -0.007 & -0.001 & $-0.067^{7 * * *}$ & -0.004 & -0.018 & 0.025 & 0.022 & $0.031^{*}$ & $0.180^{+* * *}$ & -0.016 & $0.079^{*+* * *}$ & -0.026 & -0.017 & 1.000 & \\
\hline 26 Rural area & $0.029^{*}$ & $0.032^{*}$ & 0.025 & 0.010 & 0.006 & -0.013 & -0.011 & 0.014 & 0.013 & $-0.034^{*}$ & $0.088^{* * * *}$ & $-0.044^{* *}$ & 0.009 & -0.012 & -0.005 & 0.008 & 0.000 & $-0.035^{*}$ & $0.123^{* * * *}$ & $0.190^{+3 * *}$ & $-0.071^{* * * *}$ & 0.020 & -0.013 & $0.049^{+* *+*}$ & $-0.316^{* * *}$ & 1.000 \\
\hline
\end{tabular}

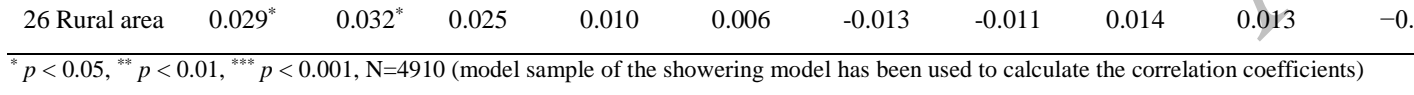




\section{References}

[1] K. Maréchal, Not irrational but habitual: the importance of "behavioural lock-in" in energy consumption, Ecol. Econ. 69 (2010) 1104-1114. doi:10.1016/j.ecolecon.2009.12.004.

[2] W. Wood, J.M. Quinn, D.A. Kashy, Habits in everyday life: Thought, emotion, and action., J. Pers. Soc. Psychol. 83 (2002) 1281-1297. doi:http://dx.doi.org/10.1037/00223514.83.6.1281.

[3] T. Dietz, G.T. Gardner, J. Gilligan, P.C. Stern, M.P. Vandenbergh, Household actions can provide a behavioral wedge to rapidly reduce US carbon emissions, Proc. Natl. Acad. Sci. 106 (2009) 18452-18456. doi:10.1073/pnas.0908738106.

[4] E. Shove, Converging conventions of comfort, cleanliness and convenience, J. Consum. Policy. 26 (2003) 395-418.

[5] K. Gram-Hanssen, Consuming technologies - developing routines, J. Clean. Prod. 16 (2008) 1181-1189.

[6] A. Darnton, B. Verplanken, P. White, L. Whitmarsh, Habits, Routines and Sustainable Lifestyles: A Summary Report to the Department for Environment, Food and Rural Affairs, AD Research \& Analysis for Defra, London, 2011.

[7] A.L. Browne, M. Pullinger, W. Medd, B. Anderson, Patterns of practice: a reflection on the development of quantitative/mixed methodologies capturing everyday life related to water consumption in the UK, Int. J. Soc. Res. Methodol. 17 (2014) 27-43.

[8] B. Karlin, N. Davis, A. Sanguinetti, K. Gamble, D. Kirkby, D. Stokols, Dimensions of Conservation: Exploring Differences Among Energy Behaviors, Environ. Behav. 46 (2012) 423-452. doi:10.1177/0013916512467532.

[9] T. Kurz, B. Gardner, B. Verplanken, C. Abraham, Habitual behaviors or patterns of practice? Explaining and changing repetitive climate-relevant actions, Wiley Interdiscip. Rev. Clim. Change. 6 (2015) 113-128.

[10] J.M. Boldero, G. Binder, Can psychological and practice theory approaches to environmental sustainability be integrated?, Environ. Plan. A. 45 (2013) 2535-2538. doi:10.1068/a130196c.

[11] E. Shove, M. Pantzar, M. Watson, The Dynamics of Social Practice: Everyday Life and How It Changes, SAGE Publications, London, 2012.

[12] A. Reckwitz, Toward a theory of social practices: a development in culturalist theorizing, Eur. J. Soc. Theory. 5 (2002) 243-263.

[13] L. Piscicelli, T. Cooper, T. Fisher, The role of values in collaborative consumption: insights from a product-service system for lending and borrowing in the UK, J. Clean. Prod. 97 (2015) 21-29. doi:10.1016/j.jclepro.2014.07.032.

[14] L. Piscicelli, M. Moreno, T. Cooper, T. Fisher, The Individual-Practice Framework: A Design Tool for Understanding Consumer Behaviour, in: A. Genus (Ed.), Sustain. Consum., Springer, Cham, 2016: pp. 35-50. doi:10.1007/978-3-319-29665-4_3.

[15] N.J. Spurling, A. McMeekin, D. Southerton, E.A. Shove, D. Welch, Interventions in practice: re-framing policy approaches to consumer behaviour, Sustainable Practices Research Group, 2013. http://eprints.lancs.ac.uk/85608/ (accessed April 3, 2018).

[16] N.F. Pidgeon, I. Lorenzoni, W. Poortinga, Climate change or nuclear power-No thanks! A quantitative study of public perceptions and risk framing in Britain, Glob. Environ. Change. 18 (2008) 69-85. doi:10.1016/j.gloenvcha.2007.09.005.

[17] A. Smith, R. Raven, What is protective space? Reconsidering niches in transitions to sustainability, Res. Policy. 41 (2012) 1025-1036. doi:10.1016/j.respol.2011.12.012.

[18] P. Burger, V. Bezençon, B. Bornemann, T. Brosch, V. Carabias-Hütter, M. Farsi, S.L. Hille, C. Moser, C. Ramseier, R. Samuel, D. Sander, S. Schmidt, A. Sohre, B. Volland, Advances in understanding energy consumption behavior and the governance of its change - outline of an integrated framework, Front. Energy Res. 3 (2015) 1-19. 
doi:https://doi.org/10.3389/fenrg.2015.00029.

[19] L. Piscicelli, Do I share because I care? The role of values in the acceptance, adoption and diffusion of collaborative consumption, doctoral thesis, Nottingham Trent University, 2016. http://irep.ntu.ac.uk/id/eprint/27945/ (accessed February 28, 2017).

[20] N. Nash, L. Whitmarsh, S. Capstick, T. Hargreaves, W. Poortinga, G. Thomas, E. Sautkina, D. Xenias, Climate-relevant behavioral spillover and the potential contribution of social practice theory, Wiley Interdiscip. Rev. Clim. Change. 8 (2017). doi:10.1002/wcc.481.

[21] I. Ajzen, The theory of planned behavior, Organ. Behav. Hum. Decis. Process. 50 (1991) 179-211.

[22] D. Evans, Attitudes, values and culture: qualitative approaches to "values" as an empirical category, http://resolve.sustainablelifestyles.ac.uk/sites/default/files/RESOLVE_WP_04-07.pdf (accessed February 28, 2017).

[23] R.B. Cialdini, R.R. Reno, C.A. Kallgren, A focus theory of normative conduct: recycling the concept of norms to reduce littering in public places, J. Pers. Soc. Psychol. 58 (1990) 1015-1026.

[24] S. Bamberg, G. Möser, Twenty years after Hines, Hungerford, and Tomera: A new meta-analysis of psycho-social determinants of pro-environmental behaviour, J. Environ. Psychol. 27 (2007) 14-25.

[25] L. Steg, G. Perlaviciute, E. van der Werff, Understanding the human dimensions of a sustainable energy transition, Front. Psychol. 6 (2015).

[26] S.H. Schwartz, Universals in the content and structure of values: theoretical advances and empirical tests in 20 countries, in: M.P. Zanna (Ed.), Adv. Exp. Soc. Psychol., Elsevier Inc, San Diego, 1992: pp. 1-65.

[27] S.H. Schwartz, Are there universal aspects in the structure and contents of human values?, J. Soc. Issues. 50 (1994) 19-45.

[28] L. Steg, G. Perlaviciute, E. van der Werff, J. Lurvink, The significance of hedonic values for environmentally relevant attitudes, preferences, and actions, Environ. Behav. 46 (2014) 163-192.

[29] T.R. Schatzki, The Site of the Social: A Philosophical Account of the Constitution of Social Life and Change, Penn State University Press, 2002.

[30] C. Tobler, V.H.M. Visschers, M. Siegrist, Consumers' knowledge about climate change, Clim. Change. 114 (2012) 189-209.

[31] L. Whitmarsh, G. Seyfang, S. O’Neill, Public engagement with carbon and climate change: to what extent is the public "carbon capable”?, Glob. Environ. Change. 21 (2011) 56-65.

[32] A. Bandura, Self-efficacy: toward a unifying theory of behavioral change, Psychol. Rev. 84 (1977) 191-215.

[33] S. Bamberg, P. Schmidt, Incentives, morality, or habit?: predicting students' car use for university routes with the models of Ajzen, Schwartz, and Triandis, Environ. Behav. 35 (2003) 264-285.

[34] SCCER CREST, Work Package 2: Change of Behaviour, (2015). http://www.sccer-crest.ch/research/ (accessed April 25, 2016).

[35] intervista AG, The intervista online access panel, (2016). https://www.intervista.ch/en/panel (accessed August 22, 2016).

[36] S. Weber, P. Burger, M. Farsi, A.L. Martinez-Cruz, M. Puntiroli, I. Schubert, B. Volland, Swiss Household Energy Demand Survey (SHEDS): objectives, design, and implementation, (2017). http://www.sccercrest.ch/fileadmin/FILES/Datenbank_Personen_Projekte_Publikationen/Publications/Wor king_Papers/Work_Package_2/Weber_Burger_et_al_2017_SHEDS_Official_description. pdf (accessed November 6, 2017).

[37] P. Bertoldi, B. Atanasiu, Electricity consumption and efficiency trends in European Union, 2009. 
http://iet.jrc.ec.europa.eu/sites/default/files/documents/ie_energy_press_event/status_repo rt_2009.pdf (accessed July 11, 2017).

[38] REMODECE, Residential monitoring to decrease energy use and carbon emissions in Europe, n.d. https://ec.europa.eu/energy/intelligent/projects/sites/ieeprojects/files/projects/documents/remodece_publishable_report_en.pdf (accessed July 11, 2017).

[39] A. de Almeida, P. Fonseca, B. Schlomann, N. Feilberg, Characterization of the household electricity consumption in the EU, potential energy savings and specific policy recommendations, Energy $\quad$ Build. $43 \quad$ (2011) 1884-1894. doi:10.1016/j.enbuild.2011.03.027.

[40] J. Nipkow, Der typische Haushalt-Stromverbrauch, Schweizerische Agentur für Energieeffizienz S.A.F.E., Zürich, 2013. http://www.safe.esense.ch/safech/studien/studien_messungen (accessed April 12, 2017).

[41] P. Benito, S. Mudgal, D. Dias, V. Jean-Baptiste, M.A. Kong, D. Inman, M. Muro, Water Efficiency Standards, Bio Intelligence Service and Cranfield University, 2009. http://ec.europa.eu/environment/water/quantity/pdf/Water\%20efficiency\%20standards_St udy2009.pdf (accessed July 11, 2017).

[42] WEMF/REMP, MACH Consumer 2015, Bevölk. Schweiz Nach Besitz Von Elektr. Haushaltsgeräten Im Haushalt Den Jahren 2014 2015. (2015). http://de.statista.com/statistik/daten/studie/387376/umfrage/umfrage-in-der-schweiz-zumbesitz-von-haushaltsgeraeten/ (accessed July 5, 2016).

[43] S. Kolenikov, Confirmatory factor analysis using confa, Stata J. 9 (2009) 329-373.

[44] A. Diekmann, R. Meyer, ETH-Studie Schweizer Umweltsurvey 2007. Klimawandel, ökologische Risiken und Umweltbewusstsein in der Schweizerischen Bevölkerung, 2007.

[45] H. Bruderer Enzler, A. Diekmann, Environmental impact and pro-environmental behavior: correlations to income and environmental concern, ETH Zurich Sociol. Work. Pap. 9 (2015) 1-35.

[46] J.C. Sweeney, J. Kresling, D. Webb, G.N. Soutar, T. Mazzarol, Energy saving behaviours: development of a practice-based model, Energy Policy. 61 (2013) 371-381.

[47] B. Jann, Making regression tables from stored estimates, Stata J. 5 (2005) 288-308.

[48] B. Jann, Making regression tables simplified, Stata J. 7 (2007) 227-244.

[49] P. Bourdieu, The Social Space and the Genesis of Groups, Theory Soc. 14 (1985) 723-744.

[50] T.R. Schatzki, Practices and Actions. A Wittgensteinian Critique of Bourdieu and Giddens, Philos.Soc. Sci. 27 (1997) 283-308. doi:10.1177/004839319702700301.

[51] W. Poortinga, L. Steg, C. Vlek, Values, Environmental Concern, and Environmental Behavior: A Study into Household Energy Use, Environ. Behav. 36 (2004) $70-93$.

[52] C. Wilson, H. Dowlatabadi, Models of decision making and residential energy use, Annu. Rev. Environ. Resour. 32 (2007) 169-203.

[53] F. Bartiaux, L.R. Salmón, Family Dynamics and Social Practice Theories: An Investigation of Daily Practices Related to Food, Mobility, Energy Consumption, and Tourism, Nat. Cult. 9 (2014) 204-224. doi:10.3167/nc.2014.090206.

[54] P.C. Stern, How can social science research become more influential in energy transitions?, Energy Res. Soc. Sci. 26 (2017) 91-95. doi:10.1016/j.erss.2017.01.010.

[55] B. Gatersleben, L. Steg, C. Vlek, Measurement and determinants of environmentally significant consumer behavior, Environ. Behav. 34 (2002) 335-362.

[56] BFS, Durchschnittsalter der ständigen Wohnbevölkerung nach Staatsangehörigkeitskategorie, Geschlecht und Kanton, (2016). https://www.bfs.admin.ch/bfs/de/home/statistiken/katalogedatenbanken/tabellen.assetdetail.291224.html (accessed June 12, 2017).

[57] BFS, Ständige Wohnbevölkerung, 
https://www.bfs.admin.ch/bfs/de/home/statistiken/bevoelkerung.html (accessed June 12, 2017).

[58] BFS, Ständige Wohnbevölkerung nach Hauptsprachen und Sprachregion, (2017). https://www.bfs.admin.ch/bfs/de/home/statistiken/kataloge-

datenbanken/tabellen.assetdetail.2220375.html (accessed June 12, 2017).

[59] BFS, Bau- und Wohnungswesen - Die wichtigsten Zahlen, (2016). http://www.bfs.admin.ch/bfs/portal/de/index/themen/09/01/key.html (accessed August 9, 2016).

[60] BFS, Household income and expenditure,

(2016).

population/income-consumption-wealth/household-budget.html (accessed March 1, 2017).

[61] BFS, Statistischer Atlas der Schweiz - Durchschnittliche Haushaltsgrösse, 2015, (2016). https://www.atlas.bfs.admin.ch/maps/13/de/12097_3046_3032_70/20029.html (accessed June 12, 2017). 